\title{
Jogos virtuais no ensino: usando a dengue como modelo
}

\author{
Virtual games on the teching and learning process: \\ using the dengue fever as a theme
}

\author{
Thais Dutra Silva \\ Fernanda Serpa Cardoso \\ Carlos Rangel Rodrigues \\ Maria Izabel Liberto \\ Maulori Currié \\ Marcos André Vannier \\ Helena Carla Castro
}

\begin{abstract}
Resumo
Atualmente a tecnologia computacional presente em algumas escolas tem sido utilizada como ferramenta de aprendizagem apenas na área de informática, ignorando este recurso como um dos mais atrativos para o público infanto-juvenil também para outras áreas do ensino. Nosso objetivo é analisar a interatividade e aceitação de jogos computacionais sobre a dengue, uma das doenças virais que mais matam no mundo, pelo público infanto-juvenil em espaços formais e nãoformais dos estados do Rio de Janeiro e Bahia. Testes com 550 alunos escolas de 10 e 20 grau revelaram que $100 \%$ aprovam os jogos virtuais como ferramenta de ensino, preferindo-os a livros, folhetos ou jogos de tabuleiro normalmente utilizados, similar ao observado em espaços não-formais. Este trabalho serve de ponto de apoio para a reflexão sobre uma maior utilização de softwares educativos e do computador nas escolas como recursos didáticos auxiliares também em outras áreas, como a biologia e a química.
\end{abstract}

Palavras-chave: dengue, computador, alunos, jogo, escola 


\begin{abstract}
Although the computational technology is highly attractive for children and teenagers, at some schools only informatics teacher has used it as a teaching tool. Our goal is to observe the student acceptance and interactivity with games containing digital information about the dengue fever, one of the most lethal viral diseases, in formal and non-formal rooms in states of Rio de Janeiro and Bahia. Tests with 550 students from first and second grade schools revealed that $100 \%$ prefer games than books, magazines or table games currently used on that purpose. Similar result was observed in non-formal places. This work suggested that the computer and software could be a high interactive didactic tool for other areas such as biology and chemistry.
\end{abstract}

Keywords: dengue fever, computer, student, game, school.

\title{
Introdução
}

\section{Jogos e Ensino}

Os jogos sempre constituíram uma forma de atividade inerente ao ser humano, representando uma ferramenta de entretenimento, raciocínio, diversão e integração social desde o seu início. Através de uma atividade lúdica como o jogo, é possível recriar uma realidade, moldá-la e, de certa maneira, vivenciá-la (PIAGET apud, RIZZI, 1997).

Piaget, em diversas obras, relata experiências lúdicas aplicadas à criança, citando os jogos como base para uma assimilação funcional e um exercício de ações individuais já aprendidas durante a vida da criança, gerando ainda um sentimento de prazer pela ação lúdica em si e pelo domínio sobre as ações realizadas (PIAGET apud, RIZZI, 1997). Assim, os jogos poderiam apresentar dupla função: consolidar os esquemas já formados inclusive a linguagem, dar prazer emocional, iniciativa e autoconfiança à criança (WYGOTSKY, 1989, FARIA, 1995). Durante todas as fases da infância, muitas modalidades de jogos estão presentes. Dentre elas, podemos citar:

a) os jogos sensório-motores, que se iniciam nos primeiros anos de vida e onde a finalidade é o próprio prazer de algumas habilidades fisiológicas. Estes são exercícios repetidos de gestos e movimentos simples, que geralmente têm início na fase maternal e duram até os dois anos, podendo ainda manter-se durante toda a infância (ex: a brincadeira de "o mestre mandou");

b) os jogos simbólicos surgem a partir dos 2 anos e têm como função a assimilação da realidade (PIAGET apud, RIZZI, 1997). Esses jogos de "faz-de-conta" possibilitam à criança a realização de sonhos e fantasias, além de revelar conflitos, medos e angústias, aliviando tensões e frustrações. De um modo geral, são excelentes para uma observação apurada dos educadores (pais e 
professores), pois a criança tende a reproduzir neles as relações presentes em seu cotidiano que somente ela seria capaz de expressar;

c) aos 7 anos, há o início de outras formas de expressão, como desenhos, representações teatrais, trabalhos manuais etc. Para esta etapa do desenvolvimento, Piaget afirma que os jogos de construção não definem uma fase entre outras, mas parecem ocupar, no segundo e no terceiro nível, uma posição situada a meio caminho entre o jogo e o trabalho inteligente (PIAGET, apud RIZZI, 1997);

d) o jogo de regras começa para crianças a partir de 5 anos e ganha força entre 7 e 12 anos, mas pode estar presente durante toda a vida do indivíduo (ex: baralho). Neles, há um conjunto de leis a serem obedecidas e seu descumprimento geralmente acarreta em uma penalização, o que propicia uma forte competição entre os jogadores. Muitas vezes, o jogo pressupõe a existência de parceiros ou grupos, conferindo-Ihe um caráter social de integração.

No processo educativo, as atividades de jogos tiveram um desenvolvimento lento; contudo, hoje sabe-se que a sua utilização no ambiente escolar traz muitas vantagens tanto para o ensino quanto para a aprendizagem (PIEROZAN e BRANCHER, 2004). É igualmente importante considerar os objetivos indiretos que o jogo pode propiciar, como os trabalhos de: memorização, orientação temporal e espacial, coordenação motora, percepção visual (cor, tamanho, detalhes, forma, posição, lateralidade), raciocínio lógico, expressão lingüística (oral e escrita), planejamento e organização das ações; enfim, o trabalho contínuo das habilidades cognitivas e motoras. No campo da socialização, a participação em jogos também contribui para a formação de atitudes como a cooperação, a obediência às regras, o senso de responsabilidade e a iniciativa pessoal e grupal.

Por ter um valor educacional intrínseco, os jogos podem ser utilizados como recursos pedagógicos (material paradidático). Os jogos funcionam como uma motivação a mais, que une a vontade e o prazer na realização de uma atividade; desta forma, o ensino utilizando meios lúdicos cria um ambiente gratificante e atraente para o desenvolvimento integral do educando. No ensino de Biologia, os jogos didáticos podem ser utilizados em sala de aula para apresentar um conteúdo, ilustrar aspectos importantes ou revisar pontos-chave. Para muitos alunos, as atividades lúdicas são mais interativas e produtivas que os costumeiros "exercícios de revisão". Entretanto, a eficácia destes passa inevitavelmente pela elaboração de um planejamento adequado para a sua aplicação, por um estudo prévio de todas as possibilidades que ele oferece e, finalmente, por uma pré-testagem (teste-piloto), onde o professor vivenciará a situação do jogo antes de incluí-la amplamente em sua prática docente. 
Há vários fatores que afetam o sucesso do programa de computador em sala de aula (BITTENCOURT, 1998) Isto significa que é essencial que uma estrutura racionalizada deva ser utilizada quando um programa educacional é desenhado, desenvolvido e avaliado, especialmente quando o veículo é o computador (LÉVY, 1998). Em particular, parece haver uma falta de atenção sobre o que os professores realmente querem em termos de software educacional (BALACHEFF, 1991). A opinião destes profissionais geralmente não tem sido avaliada e normalmente, estes profissionais estão desapontados porque não encontram um programa de computador que aborde um tema específico do currículo escolar (TAYLOR, 1996, CROSIER et al 1998). Alguns autores enfatizam a importância do desenho interativo onde o material deve ser testado pelos alunos, reavaliado e testado de novo e o ciclo deve se repetir o quanto for necessário. Na opinião destes autores, a única maneira de saber como os alunos vão usar o material e que problemas surgirão, é vê-los usando, tendo então a oportunidade de corrigi-lo (SCANLON et al., 2000).

\section{Dengue Como Tema de Ensino}

A dengue é um sério problema de saúde pública em todo o mundo, especialmente nos países tropicais como o Brasil, onde as condições do meio ambiente, aliado a características urbanas, favorecem o desenvolvimento e a proliferação do mosquito transmissor, o Aedes aegypti. Mais de 100 países em todos os continentes registram a presença do mosquito e casos da doença (THOMAS et al., 2003 e ROTHMAN, 2004).

Esta patologia é uma doença febril aguda, de etiologia viral (Flavivirus), de evolução benigna na sua forma clássica, e grave quando se apresenta na forma hemorrágica. É considerada hoje como a mais importante arbovirose que afeta o homem e representa um sério problema de saúde pública. A transmissão da doença se faz pela picada de fêmeas dos mosquitos da espécie Aedes aegypti, no ciclo homem-A. aegypti-homem. Após ter picado um indivíduo infectado, o mosquito só estará apto para transmitir o vírus, depois do período de incubação extrínseca (de 8 a 12 dias) (GUZMAN e KOURI, 2004).

Datando de 1685, o primeiro caso de dengue no Brasil foi descrito em Recife havendo ainda referências de epidemias de dengue em 1916, em São Paulo e em 1923, em Niterói, sem diagnóstico laboratorial. Desde esse primeiro relato, ocorreram a histórica atuação de Oswaldo Cruz, que iniciou a campanha contra a febre amarela no RJ em 1903; e a ampla campanha de combate ao Aedes aegypti em 1957, que declarou essa doença erradicada do país, na XV Conferência Sanitária Pan-americana. Entretanto, outras epidemias foram documentadas após 
esta declaração até hoje, sendo a mais importante ocorrida no verão de 1986/1987 no Rio de Janeiro, onde se estima que, pelo menos 1 milhão de pessoas foram contaminadas pelo sorotipo DEN 1. A introdução dos sorotipos 2 e 3 foi detectada, respectivamente, em 1990 e 2001, no estado do Rio de Janeiro, de onde foram disseminados para outras regiões do país (TEIXEIRA et al., 2001). Nos últimos anos, o governo brasileiro tem investido cada vez mais no combate à dengue. De 1996 até agora, os recursos federais destinados às ações de combate à dengue totalizam cerca de R\$ 2,5 bilhões (FUNDAÇÃO NACIONAL DE SAÚDE, 2005). A explosão do crescimento da epidemia nos verões de 2001/2002 fez com que diversas campanhas educativas que já vinham sendo desenvolvidas fossem ainda mais incrementadas com atividades e ações coordenadas envolvendo escolas, alunos, pais e professores, bem como o desenvolvimento de instrumentos diversos para problematização do tema e educação científica, envolvendo atividades de ciência, educação e arte, com produção e distribuição de folhetos e manuais (PITTA e OLIVEIRA, 1996, VALLA, 1998). A prevenção e o combate ao Aedes aegypti se mostra necessário atualmente principalmente pelo risco de desenvolvimento da dengue hemorrágica, forma letal da doença, e também por causa do perigo iminente da reemergência da Febre Amarela nos ambientes urbanos, visto que esta doença é transmitida homem a homem por intermédio da mesma espécie de artrópode. Desta forma, este processo exige a participação e a mobilização da comunidade como um todo, inclusive crianças e adolescentes que são seus futuros cidadãos, visando a interromper o ciclo de transmissão e contaminação. Durante todo esse período de combate à dengue até hoje, evidenciou-se um consenso de que o êxito de qualquer programa de controle do $A$. aegypti depende da cooperação e participação integradas da comunidade. Entretanto, para que este objetivo seja alcançado, deverão ser desenvolvidas estratégias que não só sensibilizem os formadores de opinião para a importância da ação de comunicação/educação no combate à dengue; como enfatizem a responsabilidade social no resgate da cidadania, numa perspectiva de que cada cidadão é responsável por si e pela sua comunidade. Este propósito deve ser trabalhado desde cedo nos cidadãos para estas concepções se solidifiquem e sirvam de exemplo para continuação do processo de prevenção da doença.

Em vista do significativo índice de letalidade que o vírus da dengue apresenta e sabendo que a prevenção no caso dessa patologia é fator fundamental para seu controle, o tema foi escolhido neste trabalho para demonstrar que, o uso de recursos computacionais, que até agora tem sido minimamente considerado, como ferramenta para criar novas formas de divulgação sobre essa doença, associando o desenvolvimento tecnológico com a implementação de ações de educação, poderia ser importante para aumentar o interesse que normalmente o público 
infanto-juvenil apresenta por este tópico. Com isto pretende-se que as considerações feitas sobre esta experiência sirvam de ponto de apoio para a reflexão sobre uma maior utilização de programas e jogos computacionais pedagógicos como suportes educacionais, principalmente tendo em vista a ampliação desta discussão, enfocando as relações entre estímulo, tecnologia e ensinoaprendizagem.

\section{Metodologia}

2.1. Materiais - Microcomputador Pentium III, com $128 \mathrm{mb}$ de memória, HD de 20gb, CDRW 52x lg, drive de $1.44 \mathrm{mb}$, rede e som compartilhados, teclado ABNT -2 genius, mouse genius, gabinete ATX torre media com fonte de 450w, monitor de 15" Samsung 551 v . CDs e disquetes.

\subsection{Produção dos Jogos}

Etapa 1 - Produção de um banco de dados sobre aspectos relacionados à dengue e uma biblioteca de símbolos, desenhos, sons e animações, a partir de respostas obtidas em um questionário passado em escolas públicas e privadas.

Etapa 2 - Utilização de metodologias de computação gráfica como o programa Macromedia Flash 5.0 incorporando diferentes níveis de complexidade com relação aos seguintes tópicos: movimentação gráfica, níveis de acesso de memória, complexidade e interatividade, fazendo ainda parte as seguintes etapas: Importação dos elementos do programa, Determinação das imagens que serão utilizadas para decorar os níveis do programa, Definição das texturas animadas destas imagens (Criação das animações), Criação de elementos móveis, Criação do comportamento dos elementos móveis, Criação dos níveis do programa, Validação dos níveis para o programa, Testes de funcionamento programa, Compilação do programa para uma função autônoma, Criação da versão final.

Etapa 3 - Produção dos jogos lúdicos para computador, compostos do material oriundo da biblioteca, sendo auto-executáveis.

\section{Resultado}

Inicialmente um questionário contendo 20 perguntas envolvendo questões importantes, como os causadores e vetores da dengue, forma de transmissão, envolvimento do lixo e sujeira na dengue, e papel do agente sanitário, foi ministrado para alunos de colégios público $(n=141)$ e 
privado $(n=115)$ para definir inicialmente as concepções deficientes sobre o tema dengue antes do desenvolvimento dos jogos (Tabela 1). Observa-se uma deficiência clara quanto a forma de contaminação, o que é e/ou quem é vetor, a relação da limpeza de forma direta com a contaminação, e questão do real causador da doença (vírus), dentre outros (Tabela 1). De forma interessante, apesar do professor não ser considerado a pessoa mais confiável para informar sobre a dengue, segundo opinião dos alunos entrevistados, ele seria a pessoa escolhida para a tarefa, caso pudessem determinar esta questão (Tabela 1).

Com base nestes dados, cinco jogos foram construídos seguindo princípios científicos que orientaram a construção dos mesmos e as questões envolvendo a dengue (Tabela 2). Assim jogos sobre o vírus, a limpeza dos focos de mosquitos e o nosso papel na prevenção da doença, o papel do agente de saúde e do fumacê foram construídos, e testes-piloto foram realizados tanto em espaços formais (Colégio Estadual Guilherme Briggs, Centro Educacional Niterói - Centrinho, Colégio Salesiano Santa Rosa, Escola Polivalente de Aratú) e não-formais (Expo-interativa-RJ, Dia D da dengue-Ba, Semana Ciência e Tecnologia-Ba) (Figura 1).

Os resultados da avaliação com 550 alunos mostraram que os jogos envolvendo a relação entre limpeza e prevenção e agente de saúde e fumacê foram os jogos de maior aceitação em contraste com os demais, onde o grau de facilidade e dificuldade parece ter influenciado na aceitação dos mesmos (Tabela 2). Os jogos foram entendidos (sinais, símbolos e mensagens) por alunos de 7-15 anos, enquanto que alunos de faixas etárias menores puderam jogar mais não compreenderão algumas figuras ou mensagens transmitidas pelos jogos. Isto mostra que ainda é necessário criar versões que facilite o trabalho do tema com crianças menores. Estes jogos atualmente podem ser obtidos e se encontram disponíveis para uso através do pedido ao e-mail labiomol2003@yahoo.com.br.

A escola tem o compromisso social de desenvolver a capacidade do pensamento crítico do ser humano. Por sua vez, a construção de um modelo racionalmente correto, social e politicamente justo, entre outros aspectos, induz a utilização de tecnologias inovadoras e a adoção de práticas que possibilitem ações mais participativas e democráticas (BRASIL PCNs, 2002). Os processos didático-pedagógicos tradicionalmente utilizados nas escolas às vezes não atendem as exigências dos alunos por um ensino mais dinâmico e motivador, sendo assim, o uso da Informática na Educação é uma ferramenta de apoio a esta situação (MEDEIROS E MEDEIROS, 2002, RODRIGUES, 1999). Com os recentes avanços das tecnologias da informação e da comunicação, notadamente a Internet, o computador passou a ser um instrumento muito importante na área educacional, 
facilitando o acesso ao conhecimento, informação e aprendizagem através de uma variedade maior de recursos, tais como texto, imagens, som (TRENTIN et al., 1999; GIANNELLA et al., 2001). Juntamente com este avanço tecnológico, vemos crescer as preocupações com as questões de saúde pública (especificamente sobre dengue e febre amarela) e a necessidade de conscientizar e informar a população de como prevenir o aparecimento de novas epidemias através do controle do vetor como no caso da dengue onde o mosquito Aedes Aegypti ainda é o principal alvo do combate a esta doença. Este trabalho mostra a produção de jogos que pretendem servir como veículos facilitadores para o ensino deste tema.

Tabela 1: Resultados do questionário utilizado nas investigações de concepções sobre a dengue em turmas de $5^{a} 6^{a}$ e $7^{a}$ séries de colégios públicos ( $n=141)$ e privados ( $n=115)$.

Perguntas

\begin{tabular}{|c|c|}
\hline 1a e $2^{\text {a }}$ palavras que pensa quando ouve falar em dengue & $\begin{array}{l}\text { - Doença }(69 \%) \\
\text { - Mosquito (23\%) } \\
\text { - Outras (8\%) }\end{array}$ \\
\hline $\begin{array}{l}\text { 1a providência que toma quando desconfia que está com } \\
\text { dengue? }\end{array}$ & $\begin{array}{l}\text { - Ir ao médico }(88 \%) \\
\text { - Outras }(12 \%)\end{array}$ \\
\hline O que faz ao confirmar que está com dengue? & $\begin{array}{l}\text { - Toma remédio (35\%) } \\
\text { - Vai para o hospital } \\
(23 \%) \\
\text { - Não sabe }(23 \%) \\
\text { - Outras }(9 \%)\end{array}$ \\
\hline Qual o causador da dengue? & $\begin{array}{l}\text { - Respostas envolvendo } \\
\text { a água (53\%) } \\
\text { - Mosquito (45\%) } \\
\text { - Outros (2\%) }\end{array}$ \\
\hline A dengue pode ser transmitida de humanos para humanos? & $\begin{array}{l}\text { - Sim (33\%) } \\
- \text { Não (67\%) }\end{array}$ \\
\hline $\begin{array}{l}\text { A dengue pode ser transmitida pelo contato direto com a } \\
\text { água contaminada? }\end{array}$ & $\begin{array}{l}-\operatorname{Sim}(81 \%) \\
- \text { Não }(19 \%)\end{array}$ \\
\hline
\end{tabular}




\begin{tabular}{|c|c|}
\hline A dengue é uma doença viral, bacteriana ou mosquital? & $\begin{array}{l}\text { - Viral (5\%) } \\
\text { - Bacteriana (5\%) } \\
\text { - Mosquital (90\%) }\end{array}$ \\
\hline O lixo pode facilitar a prevalência dos focos dos mosquitos? & $\begin{array}{l}\text { - Sim (80\%) } \\
\text { - Não (15\%) } \\
\text { - Não sei }(5 \%)\end{array}$ \\
\hline Qual o vetor da dengue? & $\begin{array}{l}\text { - Não sei }(63 \%) \\
\text { - água }(26 \%) \\
\text { - mosquito }(11 \%)\end{array}$ \\
\hline Quais os sintomas da dengue hemorrágica? & $\begin{array}{l}\text { - Não sei (52\%) } \\
\text { - Pode matar (21\%) } \\
\text { - Febre(15) } \\
\text { - Sangramento (10\%) }\end{array}$ \\
\hline Se você tiver hábitos de higiene isso o protegerá da dengue? & $\begin{array}{l}-\operatorname{Sim}(27 \%) \\
- \text { Não (73\%) }\end{array}$ \\
\hline $\begin{array}{l}\text { Se o agente sanitário estiver na sua casa ele vai deixá-la } \\
\text { completamente protegida dos mosquitos? }\end{array}$ & $\begin{array}{l}-\operatorname{Sim}(50 \%) \\
\text { - Não (50\%) }\end{array}$ \\
\hline $\begin{array}{l}\text { Em quem você confiaria mais para te informar sobre a } \\
\text { dengue professores ou agentes sanitários? }\end{array}$ & $\begin{array}{l}\text { - Sanitário (95\%) } \\
\text { - Professor (5) }\end{array}$ \\
\hline $\begin{array}{l}\text { Quem você gostaria que lhe informasse sobre a dengue, } \\
\text { professores ou agentes sanitários? }\end{array}$ & $\begin{array}{l}\text { - Sanitário (7\%) } \\
\text { - Professor (93\%) }\end{array}$ \\
\hline $\begin{array}{l}\text { O remédio que o agente sanitário aplica é venenoso para os } \\
\text { animais? }\end{array}$ & $\begin{array}{l}\text { - Sim (60\%) } \\
\text { - Não (40\%) }\end{array}$ \\
\hline $\begin{array}{l}\text { Se sua casa estiver limpinha ela pode virar um criadouro do } \\
\text { mosquito da dengue? }\end{array}$ & $\begin{array}{l}\text { - Sim (21\%) } \\
\text { - Não (89\%) }\end{array}$ \\
\hline No lixão podemos encontrar o mosquito da dengue? & $\begin{array}{l}-\operatorname{Sim}(75 \%) \\
\text { - Não (25\%) }\end{array}$ \\
\hline $\begin{array}{l}\text { Onde você acha que o mosquito deposita seus ovos? Na água } \\
\text { suja, na água limpa ou nos dois locais? }\end{array}$ & - Nos dois locais (75\%) \\
\hline
\end{tabular}




\begin{tabular}{|l|l|}
\hline - Na água limpa (15\%) \\
- Na água suja (10\%)
\end{tabular}

Tabela 2: Jogos produzidos e utilizados na visitas a escolas e espaços

\section{informais}

\begin{tabular}{|c|c|c|c|c|}
\hline Jogo & Elementos & Versão Final & $\begin{array}{l}\text { Questões } \\
\text { Abordadas }\end{array}$ & Formato do Jogo \\
\hline $\begin{array}{l}\text { Ajude o } \\
\text { cientista }\end{array}$ & $\begin{array}{l}\text { Cientista; } \\
\text { Seringas; } \\
\text { Vírus; } \\
\text { Vaso } \\
\text { Sangüíneo } \\
\text { (Fundo) }\end{array}$ & & $\begin{array}{l}\text {-Quem é o } \\
\text { causador da } \\
\text { dengue ? } \\
\text {-Existe vacina para } \\
\text { a dengue, contra a } \\
\text { dengue, contra o } \\
\text { mosquito ou } \\
\text { contra o vírus? } \\
\text {-Ter dengue uma } \\
\text { vez só já protege? }\end{array}$ & $\begin{array}{l}\text { O cientista viaja pelo } \\
\text { organismo lançando } \\
\text { injeções sobre os vírus, em } \\
\text { analogia aos linfócitos B } \\
\text { que liberam anticorpos. } \\
\text { Nível de dificuldade: } \\
\text { máximo em analogia ao } \\
\text { tema. }\end{array}$ \\
\hline $\begin{array}{l}\text { Fu․․ } \\
\text { Fumacê } \\
\text { Turbinado }\end{array}$ & $\begin{array}{l}\text { Carro do } \\
\text { Fumacê; } \\
\text { Cidade; } \\
\text { Mosquitos } \\
\text { (4 Espécies } \\
\text { Diferentes) }\end{array}$ & & $\begin{array}{l}\text {-O que faz o } \\
\text { agente de saúde? } \\
\text {-O que é o } \\
\text { fumacê? } \\
\text {-Somente eles são } \\
\text { a solução para o } \\
\text { controle da } \\
\text { dengue? } \\
\text {-Todo mosquito é } \\
\text { vetor da dengue? }\end{array}$ & $\begin{array}{l}\text { O fumacê durante o } \\
\text { percurso lança o veneno } \\
\text { contra os mosquitos que } \\
\text { podem ser de diversas } \\
\text { espécies. Durante o vôo, } \\
\text { os mosquitos tentam } \\
\text { eliminar seus ovos nos } \\
\text { criadouros, o que o } \\
\text { fumacê tenta evitar com o } \\
\text { veneno. } \\
\text { Nível de dificuldade: fácil a } \\
\text { médio }\end{array}$ \\
\hline
\end{tabular}




\begin{tabular}{|c|c|c|c|c|}
\hline $\begin{array}{l}\text { Dê um } \\
\text { tapa na } \\
\text { dengue }\end{array}$ & $\begin{array}{l}\text { Casa; } \\
\text { Mosquitos } \\
\text { Mão }\end{array}$ & 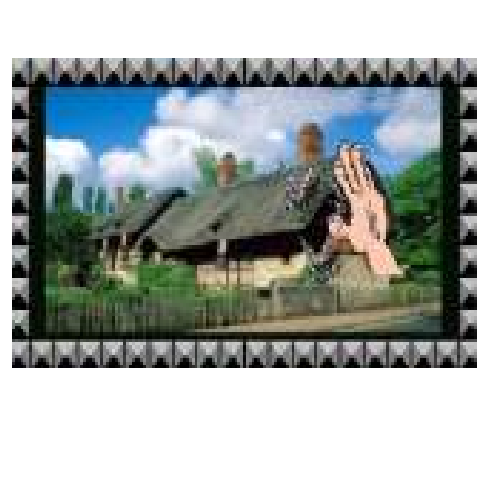 & $\begin{array}{l}\text {-Só matar } \\
\text { mosquito com a } \\
\text { mão, usando } \\
\text { inseticidas e } \\
\text { ventila dores é o } \\
\text { que resolve no } \\
\text { combate a } \\
\text { dengue? }\end{array}$ & $\begin{array}{l}\text { O jogador tenta matar os } \\
\text { mosquitos com a mão que } \\
\text { continuam a aparecer de } \\
\text { forma continuada sem } \\
\text { nunca parar. } \\
\text { Nível de dificuldade: fácil }\end{array}$ \\
\hline $\begin{array}{l}\overrightarrow{\text { Dengue }} \\
\text { Pacman }\end{array}$ & $\begin{array}{l}\text { Boneco; } \\
\text { Latas; } \\
\text { Pneus; } \\
\text { Copos; } \\
\text { Inseticida; } \\
\text { Mosquitos }\end{array}$ & 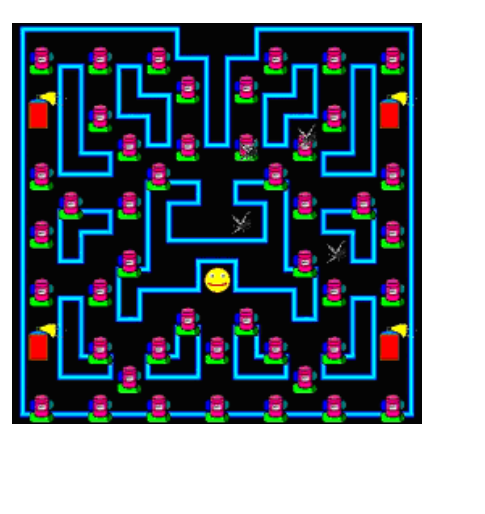 & $\begin{array}{l}\text {-Nós podemos } \\
\text { fazer alguma coisa } \\
\text { para ajudar no } \\
\text { controle da } \\
\text { dengue? } \\
\text {-Que atitudes são } \\
\text { importantes para } \\
\text { prevenir a dengue? }\end{array}$ & $\begin{array}{l}\text { O boneco coleta tudo que } \\
\text { pode se tornar } \\
\text { reservatório de água e, } \\
\text { portanto criadouro de } \\
\text { mosquitos. } \\
\text { Nível de dificuldade: } \\
\text { Possui quatro níveis de } \\
\text { dificuldade. }\end{array}$ \\
\hline
\end{tabular}

Tabela 3: Aceitação dos Jogos produzidos

\begin{tabular}{|l|l|} 
Jogo & \multicolumn{1}{l}{ Grau de aceitação } \\
\hline Ajude o cientista & $80 \%$ \\
\hline Fumacê Turbinado & $98 \%$ \\
\hline Dê um tapa na dengue & $70 \%$ \\
\hline Dengue Pacman & $100 \%$ \\
\hline
\end{tabular}

O Grau de aceitação se refere a pontuação obtida nos testes-piloto com alunos de escolas públicas e particulares, onde o jogo foi qualificado quanto à sua aceitação, preferência e entendimento. 


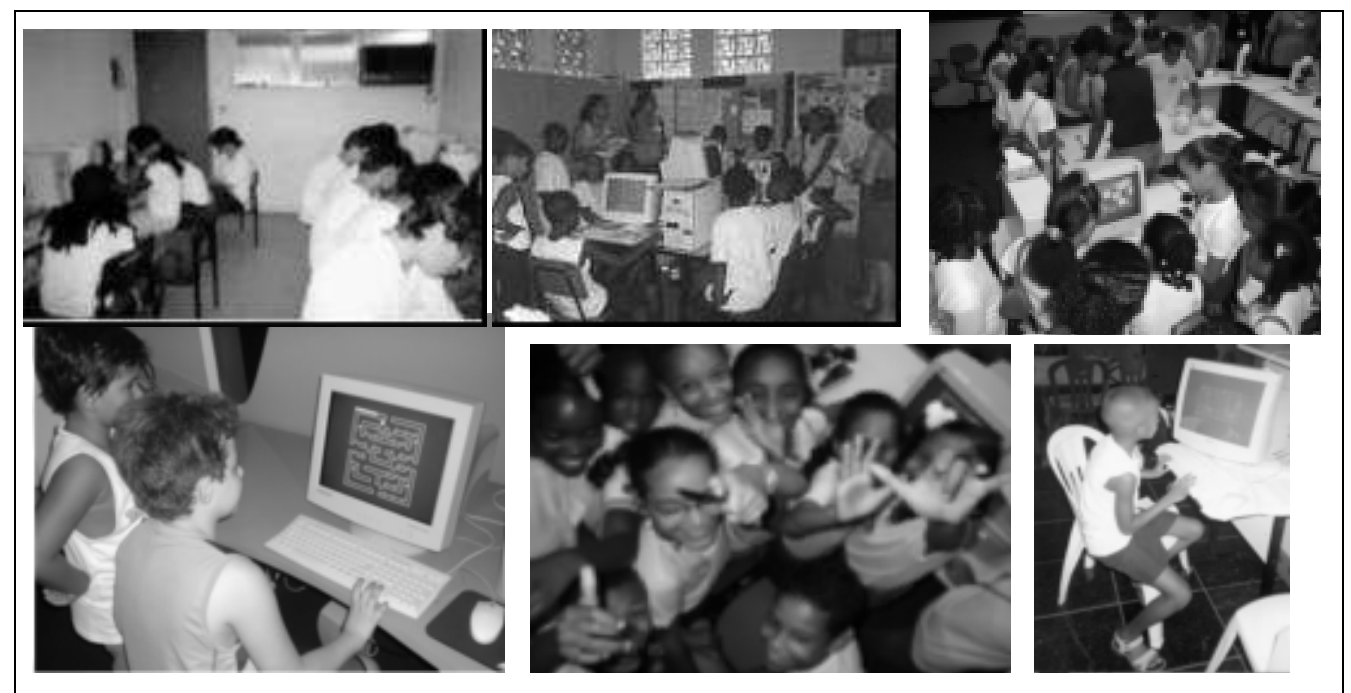

Figura 1: Fotos ilustrando as visitas em algumas escolas particulares $e$ públicas, e espaços não-formais (Expo-interativa-RJ, Dia D da dengue-BA,

Semana Ciência e Tecnologia-BA) utilizando os jogos produzidos.

\section{Referências}

BALACHEFF, N. Contribution de la didactique et de l'epistémologie aux recherches en EIAO. In: BELLISANT, C. (Ed.). Actes des XIII Journées Francophones de I'informatique. Grenoble: IMAGCNRS, p.181-215, 1991.

BITTENCOURT, Jane. Informática na educação? Algumas considerações a partir de um exemplo. Rev. Fac. Educ., vol.24, v.1, p.23-36, 1998.

BRASIL, Ministério de Educação, Secretaria de Educação Média e Tecnológica. PCN+ Ensino Médio: Orientações educacionais complementares aos Parâmetros Curriculares Nacionais. Ciências da Natureza, Matemática e suas Tecnologias. Brasília: MEC, 2002.

CROSIER, J. K., \& WILSON, J. R. Teachers' priorities for virtual learning environments in secondary science. Computers \& Education, v.38. p.77-94, 2002.

GUZMAN MG, KOURI G. Dengue diagnosis, advances and challenges. Int J Infect Dis. Mar;8(2):6980.

SCANLON, E., JONES, A., CALDER, J., BARNARD, J. e THOMPSON, J. Evaluating Information and Communication Technologies for Learning. FEEducational Technology \& Society , 3 (4) pp 101-107, 2000 . 
LÉVY, Pierre. As tecnologias da inteligência: o futuro do pensamento na era da informática. Tradução Carlos Irineu da Costa. Rio de Janeiro: Editora 34, 1998.

FUNDAÇÃO NACIONAL DE SAÚDE. Fundação Nacional de Saúde Ministério da Saúde Disponível em: < http:// www.saude.rj.gov.br/acoes/Material de Dengue (Aluno)/ModuloI.pdf > Acessada em 10 de maio 2005.

MEDEIROS, A. and MEDEIROS, C. F. de Possibilidades e Limitações das Simulações Computacionais no Ensino da Física. Rev. Bras. Ens. Fis., Jun, vol.24, no.2, p.77-86, 2002.

PIEROZAN, C; BRANCHER, JD. A importância do jogo educativo e suas vantagens no processo Ensino e Aprendizagem. Congresso Nacional de Ambientes Hipermídia para Aprendizagem (Conahpa), 2004.

PITTA, A, OLIVEIRA, V. Estratégias de comunicação frente ao desafio do Aedes aegypti no Brasil. Ciência Saúde col 1 (1) p.26-28, 1996.

RIZZI, L \& HAYDT, RC (1997). Atividades lúdicas na educação da criança. Ed. Ática, 6a edição, Série Educação.

RODRIGUES, A. M. M. Por uma filosofia da tecnologia. In: GRINSPUN, Mirian; ZIPPIN, P. S. (Org.). Educação tecnológica: desafios e perspectivas. São Paulo: Cortez, v.1. p 16-27, 1999.

ROTHMAN, AL. Dengue: Defining Protective Versus Pathologic Immunity. J Clin Invest. v.113, p.946-51, 2004.

TAYLOR, J. Moving into multimedia: Issues for teaching and learning. Innovations in Education and Training, software. Interacting with Computers, v. 11, p.499-516, 2004.

TEIXEIRA, M.G.; COSTA, M.C.N.; BARRETO, M.L.; FERREIRA, L.D.A.; VASCONCELOS, P. Validação da informação referida sobre acometimento de dengue e vigilância epidemiológica. Revista da sociedade brasileira de medicina tropical, v. 34(1): p. 60-61, 2001.

THOMAS SJ, STRICKMAN D, VAUGHN DW.Dengue epidemiology: virus epidemiology, ecology, and emergence.Adv Virus Res.v. 61, p.235-89, 2003.

VALLA, V. V., 1998. Sobre participação popular: uma questão de perspectiva. Cad. Saúde pública, rj, 14 (sup.2): 7-18.

WYGOSTKY, S. A formação social da mente. 3ạ ed., São Paulo, Martins Fontes, v.1., p.37-45, 1989 
Thais Dutra Silva - Universidade Federal Fluminense, Departamento de Biologia Celular e Molecular

thaisdunas@yahoo.com.br

Fernanda Serpa Cardoso - Universidade Federal Fluminense, Departamento de Biologia Celular e Molecular

fernandalabiomol@yahoo.com.br

Carlos Rangel Rodrigues -Universidade Federal do Rio de Janeiro, Faculdade de Farmácia rangelrodrigues2003@yahoo.com.br

Maria Izabel Liberto - Universidade Federal do Rio de Janeiro, Instituto de Microbiologia isabel@micro.ufrj.br

Maulori Currié - Universidade Federal do Rio de Janeiro, Instituto de Microbiologia maulori@micro.ufrj.br

Marcos André Vannier - Fundação Oswaldo Cruz

vannier@cpqgm.fiocruz.br

Helena Carla Castro - Universidade Federal Fluminense, Departamento de Biologia Celular e Molecular

hcastrorangel@yahoo.com.br 